\title{
Prior Biologic Therapy
}

National Cancer Institute

\section{Source}

National Cancer Institute. Prior Biologic Therapy. NCI Thesaurus. Code C15452.

Previous biologic therapy administered as treatment. 